TELEIOS: Jurnal Teologi dan Pendidikan Agama Kristen

Sekolah Tinggi Teologi Transformasi Indonesia

ISSN 2798-0642 (Online), 2798-1797 (Print)

Volume 1, Nomor 2, Desember 2021 (144-154)

DOI: 10.53674/teleios.v1i2.35

stttransformasi-indonesia.ac.id/e-journal/index.php/teleios/index

\title{
Implementasi Pemuridan Kristen dalam Keluarga di Era Disrupsi
}

\author{
${ }^{1}$ Yonathan Wingit Pramono, ${ }^{2}$ Sari Saptorini, ${ }^{3}$ Jhon Leonardo Presley Purba \\ ${ }^{1,2,3}$ Sekolah Tinggi Teologi Baptis Indonesia, Semarang \\ 1yonathanwingit@stbi.ac.id, ${ }^{2}$ sarisaptroni@stbi.ac.id, 3jhonpresley@ stbi.ac.id
}

\begin{abstract}
Abstrak:
Keluarga merupakan dasar dan tempat utama pemuridan Kristen untuk mewujudkan pertumbuhan rohani anak-anak Kristen agar siap menghadapi tantangan kehidupan di era disrupsi seperti saat ini. Menggunakan pendekatan kualitatif deskriptif dengan metode studi literature. Penelitian ini bertujuan untuk menjawab pertanyaan penelitian tentang bagaimana implementasi pemuridan Kristen di dalam keluarga di era disrupsi saat ini. Hasil penelitian menyimpulkan bawah pemuridan Kristen dalam keluarga di era disrupsi merupakan hal yang esensial dan krusial. Orang tua berperan penting melakukan pemuridan Kristen dalam keluarga untuk mendidik dan mengarahkan anak-anak Kristen menjadi generasi yang konsisten dan bertumbuh dalam iman kepada Tuhan dan menjadi murid Kristus yang sejati. Menjadi dewasa dalam kepribadian, kerohanian dan moralitas sehingga tidak mudah terjerumus ke dalam aspek negative dari perkembangan teknologi informasi digital saat ini. Dibutuhkan komitmen dan konsistensi dalam implementasi pemuridan Kristen dalam keluarga di era disrupsi untuk menghindari distraksi atau disrupsi dari berbagai informasi media digital yang ada, sebaliknya harus menyediakan waktu yang khusus untuk melakukan pemuridan dengan memanfaatkan perkembangan digitalisasi teknologi informasi di era disrupsi secara positif. Salah satunya melakukan pemuridan keluarga secara virtual. Dengan demikian pemuridan Kristen dalam keluarga tetap dapat dilakukan walaupun orang tua dan anak terpisah jarak dan tempat.
\end{abstract}

Kata Kunci: Pemuridan Kristen, Keluarga, Era Disrupsi, Amanat Agung

\begin{abstract}
:
The family is the basis and the main place for Christian discipleship to realize the spiritual growth of Christian children so that they are ready to face the challenges of life in this era of disruption. Using a descriptive qualitative approach with a literature study method. This study aims to answer research questions about how to implement Christian discipleship in families in the current era of disruption. The results of this study conclude that Christian discipleship in families in the era of disruption is essential and crucial. Parents play an important role in carrying out Christian discipleship in the family to educate and direct Christian children to become a generation that is consistent and grows the faith in God and becomes the true disciples of Christ. Become mature in personality, spirituality and morality so that it is not easy to fall into the negative aspects of the development of digital information technology today. It takes commitment and consistency in the implementation of Christian discipleship in families in the era of disruption to avoid distraction or disruption from various existing digital media information, on the contrary, must provide special time for discipleship by utilizing the development of digitalization of information technology in the
\end{abstract}


era of disruption in a positive way. One of them is doing virtual family discipleship. Thus, Christian discipleship in the family can still be done even though parents and children are separated by distance and place.

Keywords: Christian Discipleship, Family, the Era of Disruption, Great Commission

\section{Pendahuluan}

Kondisi masyarakat yang tidak menentu di era disrupsi pada masa sekarang ini semakin membutuhkan perhatian lebih dari orang tua terhadap pertumbuhan rohani bagi anak-anak dalam keluarga Kristen. Sebagaimana dinyatakan oleh Sia Kok Sin bahwa pembinaan rohani terhadap anak-anak oleh orang tua merupakan tanggungjawab yang sesuai dengan model pemuridan mendasar yang dilakukan oleh umat pilihan Tuhan dalam Perjanjian Lama. ${ }^{1}$ Namun banyak orang tua Kristen yang terlihat kurang menyediakan waktu untuk memberikan sebuah pembelajaran rohani kepada anak-anak mereka, dan banyak yang mengatakan bahwa itu adalah tugas pendeta, guru sekolah minggu, guru agama Kristen di sekolah.

Berdasarkan model pemuridan alkitabiah, dibutuhkan kesadaran dari para orang tua Kristen untuk mengambil peran penting memuridkan anak-anak di dalam keluarga seperti model keluarga Timotius, di mana Timotius dimuridkan dalam iman Kristen oleh neneknya Lois dan ibunya Eunike, yang telah meletakkan dasar dan mewariskan iman Kristen yang otentik secara turun temurun (2 Timotius 1:5). ${ }^{2}$ Prinsip yang sama juga ditekankan dalam Ulangan 6:7-8, di mana orang tua berperan penting sebagai guru yang rutin memberikan arahan, bimbingan, dan dorongan kepada anak secara terus menerus untuk hidup dan bertumbuh di dalam Tuhan. ${ }^{3}$

Bill Hull dalam buku Pemuridan Yang Berhasil menyatakan bahwa pemuridan adalah sebuah perwujudan yang dilakukan sebagai "pelatihan murid yang dalam pelaksanaannya disertai niat tanggung jawab, dasar yang dipakai dengan sebuah hubungan yang saling

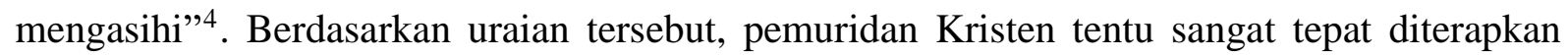
dalam keluarga Kristen melalui hubungan pemuridan antara orang tua dan anak. Tujuan dari penelitian ini adalah untuk menemukan jawaban dari rumusan masalah dalam penelitian ini yaitu bagaimana implementasi pemuridan Kristen di dalam keluarga Kristen di era disrupsi seperti saat ini.

\section{Metode Penelitian}

Penelitian ini dilakukan dengan pendekatan kualitatif dengan metode studi literature, yang adalah metode peneliti dengan mengumpulkan sebanyak mungkin teori maupun informasi dari sumber-sumber kepustakaan yaitu buku, e-book dan jurnal-jurnal penelitian terdahulu yang

\footnotetext{
${ }^{1}$ Sia Kok Sin, “Adakah Metode Pemuridan Dalam Perjanjian Lama?,” SOLA GRATIA: Jurnal Teologi Biblika dan Praktika 5, no. 1 (2020).

${ }^{2}$ Merrill Frederick Unger, The New Unger's Bible Handbook (Singapore: Moody Publisher, 2005), 982.

3 Tan Giok Lie, "Tantangan Dalam Pendidikan Dan Pengajaran Masa Kini," Jurnal Teologi Stulos 12, no. 1 (2013).

${ }^{4}$ Alton Garrison, Pemuridan Yang Berhasil (Malang: Gandum Mas Malang, 2016), 19.
} 
relevan dengan topik penelitian. Sumber-sumber yang digunakan kredibel dan valid sehingga dapat dipertanggungjawabkan secara akademik. Hal ini dilakukan untuk menjawab persoalan penelitian tentang bagaimana implementasi pemuridan Kristen di dalam keluarga di tengahtengah fenomena era disrupsi yang dihadapi saat ini. ${ }^{5}$ Sistematika penulisan paper ini dilakukan melalui langkah-langkah berikut ini. Pertama, menguraikan definisi pemuridan Kristen. Kedua, menguraikan dinamika pemuridan dalam konteks keluarga Kristen. Ketiga, menguraikan bagaimana implementasi pemuridan Kristen di era disrupsi melalui upaya pembentukan anakanak dalam keluarga Kristen untuk menjadi murid-murid Kristus dengan segala tantangan dan dinamika yang ada di era disrupsi. Keempat, menguraikan kesimpulan dari penelitian.

\section{Hasil dan Pembahasan}

Era disrupsi oleh Rhenald Kasali didefinisikan sebagai suatu bentuk transformasi sebagai dampak hadirnya masa depan ke masa kini. Kemajuan dari perkembangan teknologi yang sangat cepat berubah di dalam kehidupan masyarakat memberikan pengaruh yang positif maupun negatif untuk masyarakat secara luas. Sisi positif masyarakat sangat terbantu dengan teknologi yang memberikan informasi yang sangat cepat di semua bidang dengan sistem yang lebih maju. Sisi negatifnya, terkadang informasi yang disampaikan muncul hal-hal yang tidak sesuai dengan norma-norma suatu masyarakat. ${ }^{6}$ Menurut Daniel Ronda, di era disrupsi seperti saat ini informasi yang diterima sama sekali tidak melalui proses penyaringan, hal ini berimplikasi pada banyaknya berita bohong atau hoaks, yang memuat konten-konten provokatif bernuansa SARA, kekerasan ataupun pornografi. ${ }^{7}$ Keadaan seperti ini sangat mempengaruhi kehidupan kerohanian Kekristenan, khususnya anak-anak. Sebagaimana disimpulkan oleh Arifianto dan Santo bahwa pesatnya perkembangan media sosial di era disrupsi menjadi salah satu penyebab utama begitu mudahnya terjadi perundungan (bullying) kepada sesama khususnya anak-anak. ${ }^{8}$ Oleh karena itu, dibutuhkan peran aktif orang tua dalam membangun komunikasi yang baik dengan anak-anak di dalam keluarga agar anak-anak dapat memiliki mentalitas dan kepercayaan diri sehingga mampu menyaring dan menyikapi isu-isu yang tidak benar dari berbagai sumber informasi di era disrupsi ini. ${ }^{9}$ Dalam konteks keluarga Kristen, hal ini dapat dilakukan melalui pemuridan Kristen di dalam keluarga.

\section{Pemuridan Kristen}

Matius 28:18-20 menjadi dasar utama untuk merumuskan pengertian pemuridan Kristen, dimana Tuhan Yesus meminta para muridNya dan pengikutNya supaya memberitakan berita keselamatan (Injil) sampai ke seluruh dunia. Sebagaiman disimpulkan oleh Purwoto dan kolega bahwa di era digitalisasi 5.0 seperti saat ini pelaksanaan Amanat Agung Tuhan Yesus

\footnotetext{
${ }^{5}$ Sonny Eli Zaluchu, "Metode Penelitian Di Dalam Manuskrip Jurnal Ilmiah Keagamaan,” Jurnal Teologi Berita Hidup 3, no. 2 (2021): 249-266.

${ }^{6}$ Rhenald Kasali, Self Disruption (Jakarta: Mizan Anggota IKAPI, 2018).

${ }^{7}$ Daniel Ronda, "Kepemimpinan Kristen Di Era Disrupsi Teknologi," Evangelikal: Jurnal Teologi Injili dan Pembinaan Warga Jemaat (2019).

${ }^{8}$ Yonatan Alex Arifianto and Joseph Christ Santo, "Iman Kristen Dan Perundungan Di Era Disrupsi," Angelion: Jurnal Teologi dan Pendidikan Kristen 1, no. 2 (2020).

${ }^{9}$ Prima Frieda and H.H Daniel Tamburian, "Komunikasi Antarpribadi Antara Orang Tua Dan Anak Usia Remaja Dalam Pembentukan Kepercayaan Diri Anak," Koneksi 3, no. 2 (2020).
} 
membutuhkan inovasi baru. Jika sebelumnya aktualisasi Amanat Agung berbasis on site maka di era digital misi Amanat Agung dapat dilakukan melalui aktivitas teknologi digital. Hal ini tentu menuntut inovasi dan pengetahuan baru tentang digitalisasi dari para misionaris. ${ }^{10}$ Berkaitan dengan Amanat Agung tersebut, penjelasan Bill Hull tentang pemuridan merupakan tugas yang dilakukan untuk melakukan perintah Tuhan Yesus dalam Amanat Agung yang menekankan kata kerja "pergilah, baptislah, dan ajarlah". Kemudian tindakan utama dalam perintah Yesus adalah "jadikanlah segala suku bangsa menjadi murid-Ku" atau "membuat murid." Oleh karena itu dapat disimpulkan bahwa yang menjadi tugas utama dalam pemuridan adalah membuat seorang murid. ${ }^{11}$ Penjelasan selanjutnya oleh Bill Hull, mengenai istilah murid (disciple) kata yang berasal dari Yunani mathetes, yang memiliki arti seorang yang belajar dengan mengikuti semua perintah dari gurunya, secara tidak langsung mempengaruhi gaya hidup orang tersebut. Bill Hull mengemukakan secara spesifik lima karakteristik seorang murid, yaitu "Murid harus tunduk pada pemimpin yaitu Kristus, Murid mempelajari Firman Tuhan, Murid mempelajari bagaimana Yesus melayani, Murid mencontoh hidup dan karakter Yesus, Murid harus mencari dan mengajar murid-murid lain untuk mengikut Yesus." Penekanan dalam pemuridan dalam penjelasan oleh Hull, fokus utama Yesus adalah mengarahkan kepada perubahan kehidupan murid. ${ }^{12}$

Istilah lain dari kata murid menurut Edmund Chan adalah kata yang berasal dari Yunani, dimana kata mathetes digunakan dalam proses belajar seseorang yang mencari pengetahuan dalam bidang tertentu. Istilah murid inilah yang digunakan dalam konteks pemuridan pada zaman Yesus. ${ }^{13}$ Selain itu juga George Barna mendefinisikan kata murid, sebagai pengikut Yesus yang setia, berpengetahuan, dan pelaku firman, dengan tugas pemuridan yang akan melibatkan antara guru memperlengkapi murid, kemudian direspon oleh murid dengan mengikuti semua pengajaran dan keteladanan dari guru tersebut. ${ }^{14}$

Pemuridan menurut Bill Hull adalah sebuah cara dalam pribadi seseorang yang memiliki pengaruh positif yang berbeda dari sebelumnya pada sebuah Gereja dan masyarakat. ${ }^{15}$ Perubahan transformasi diawali dengan seseorang akan diajar oleh orang lain untuk percaya Tuhan dan menjadi muridNya. Dilanjutkan dengan belajar Alkitab mengenal lebih dalam sehingga serupa Kristus. Dalam proses selanjutnya maka orang tersebut akan meneruskan apa yang menjadi tugas yaitu mengajarkan orang lain dengan tujuan sama menjadi murid Tuhan Yesus. Dalam kehidupan Kristen sebutan murid sering dipakai dalam menjelaskan bahwa orang tersebut percaya kepada Tuhan sesuai Alkitab. Pemuridan Kristen memiliki fungsi salah satunya secara umum adalah memperlengkapi tiap-tiap pribadi, seseorang akan diperlengkapi agar terus bertumbuh dalam Yesus sehingga dapat juga memenuhi kebutuhannya. Pemuridan Kristen yang baik akan menumbuhkan kerohanian yang bersumber kepada Alkitab. Sebab sejatinya semangat pemuridan sangat diperlukan pembelajaran atau pemahaman secara teologis

${ }^{10}$ Paulus Purwoto et al., “Aktualisasi Amanat Agung Di Era Masyarakat 5.0,” DUNAMIS: Jurnal Teologi dan Pendidikan Kristiani 6, no. 1 (2021): 315-332.

${ }^{11}$ Bill Hull, Jesus Christ, Disciplemaker, 1st ed. (Surabaya: Literatur Perkantas Jawa Timur, 2015).

12 Ibid.

${ }^{13}$ Edmund Chan, A Certain Kind (Yang Tertentu): Pemuridan Intensional Yang Mengubah Definisi Sukses Dalam Pelayanan (Singapore: Covenant Evangelical Free Church, 2014), 46.

${ }^{14}$ George Barna, Menumbuhkan Murid-Murid Sejati (Jakarta: Metanoia, 2010).

${ }^{15}$ Hull, Jesus Christ, Disciplemaker. 
yang Alkitabiah dengan benar. ${ }^{16}$ Terlebih pemuridan adalah hal yang diharapkan untuk dimaksimalkan dalam dunia pelayanan orang percaya masa kini. ${ }^{17}$ Dari ketiga pendapat dari para ahli di atas menunjukkan tugas pokok dari pemuridan Kristen membuat seorang murid yang akan mampu mewujudkan kasih, keadilan, kebenaran dalam keluarga, masyarakat, dan semua aspek kehidupan.

\section{Pemuridan dalam Keluarga Kristen}

Keluarga merupakan institusi dasar yang menjadi awal dari komunitas yang lebih besar yaitu masyarakat yang memiliki struktur fungsional yang mencakup dimensi kerohanian. ${ }^{18}$ Pemeliharaan kehidupan kerohanian dalam keluarga dilakukan oleh setiap anggota-anggotanya melalui pola asuh dan pengajaran dari orang tua kepada anak-anaknya, yang dilaksanakan dengan mengikuti nilai-nilai atau norma-norma agama. Oleh sebab itu peranan keluarga menjadi sangat penting dalam mendidik anak-anak yang selalu didasarkan pada segi agama, sosial, masyarakat ataupun setiap pribadi masing-masing. ${ }^{19}$

Pemuridan Kristen dalam keluarga akan menjadi cara yang efektif untuk memberikan hasil yang positif dalam pertumbuhan rohani. ${ }^{20}$ Sistem pemuridan dalam Alkitab sudah ada di Perjanjian Lama. Ketika Musa dipilih oleh Allah sebagai pemimpin bangsa Israel, untuk membawa Israel keluar dari tanah Mesir (Keluaran 3) dengan tujuan tanah perjanjian sesuai dengan perintah Allah, Tuhan memerintahkan agar bangsa Israel mengasihi Tuhan dengan segenap hati, jiwa, dan kekuatan mereka. ${ }^{21}$ Perintah ini terdapat dalam Ulangan 6:1-10 yang dikenal dengan Shema sebuah pelaksanaan perintah yang diawali dalam masing-masing keluarga bangsa Israel. Shema dalam Ulangan 6:4-6 dapat dijadikan sebagai prinsip utama pendidikan dalam keluarga bangsa Israel. Pendidikan ini pada prinsipnya sama dengan kegiatan pemuridan dalam keluarga yang dilakukan oleh orang tua kepada anak-anak. Pemuridan dalam keluarga Israel ini harus dilakukan, khususnya dalam keluarga para imam karena bila tidak dilakukan maka akan menimbulkan aib yang sangat memalukan. Contohnya adalah seperti keluarga Imam Eli. Imam Eli gagal dalam mendidik anak-anaknya sehingga mereka hidup dengan tidak sesuai kebenaran. Namun berbeda dengan Samuel yang sejak kecil dididik oleh Imam Eli dengan baik sehingga pertumbuhan rohaninya sangat baik dan Samuel hidup berkenan di hadapan Tuhan dan manusia. ${ }^{22}$

\footnotetext{
${ }^{16}$ Listari Listari and Yonatan Alex Arifianto, "Prinsip-Prinsip Misi Dari Teks Amanat Agung Bagi Pelaksanaan Misi Gereja Masa Kini,” JURNAL TEOLOGI GRACIA DEO 3, no. 1 (2020): 42-55.

${ }^{17}$ Yonatan Alex Arifianto, Reni Triposa, and Paulus Karaeng Lembongan, "Bible Study of Mission and Discipleship in the Great Commission and Its Implications for Today's Christian Life," Diegesis : Jurnal Teologi 5, no. 2 (2020): 25-42.

${ }^{18}$ Mitha Nurjanah, “Teori Keluarga: Studi Literatur,” Article, no. July (2019).

19 Ibid.

20 Timotius Haryono, "Model Pemuridan Berbasis Keluarga Era New Normal Pandemi Covid-19," DUNAMIS: Jurnal Teologi dan Pendidikan Kristiani 5, no. 2 (2021).

${ }^{21}$ Jhon Leonardo Presley Purba and Robinson Rimun, "Kritik Terhadap Metode Tafsir Hermeneutik Pembebasan Terhadap Peristiwa Keluaran Sebagai Suatu Bentuk Pembebasan," Jurnal Teologi Amreta 4, no. 2 (2021).

${ }^{22}$ Iain Provan, V. Philips Long, and Tremper Longman III, A Biblical History of Israel (Louisville, Kentucky: Westminster John Knox Press, 2003), 252.
} 
Prinsip pemuridan dalam keluarga bangsa Israel membutuhkan perhatian yang khusus dari orang tua untuk melakukan pemuridan melalui pengajaran yang simultan dan konsisten kepada anak-anak mereka agar anak-anak tersebut dapat hidup benar. Pemuridan dalam keluarga Israel biasanya dapat dilakukan dalam berbagai kesempatan yang ada seperti waktu duduk di rumah, sedang dalam perjalanan, waktu berbaring dan bangun pagi. Karena begitu pentingnya pemuridan ini untuk dilakukan, sehingga untuk mengingatnya diberikan penekanan melalui pertintah untuk mengikatkannya sebagai tanda pada tanganmu dan menjadi lambang pada dahimu. Menuliskan perintah Allah pada tiang pintu rumahmu dan pada pintu gerbangmu. Dalam proses kerohanian bangsa Israel Allah memakai keluarga-keluarga Israel dalam mendidik anak-anak melalui orang tua, agar mendidik dengan tegas dan ketat dalam keagamaan, terstruktur dan dilakukan dengan terus-menerus dalam segala kesempatan sejak kecil. ${ }^{23}$ Pola pemuridan dalam keluarga juga tampak dalam Perjanjian Baru, salah satunya adalah yang tertulis dalam 2 Timotius 1: 5 dan 2 Timotius 3:15. Dari kedua ayat ini dapat disimpulkan bahwa Timotius mendapatkan didikan atau dimuridkan dalam keluarga oleh neneknya Lois dan ibunya Eunike dalam kebenaran Firman Tuhan (Kitab Suci). Pola pemuridan ini sudah dipersiapkan oleh Tuhan Yesus sejak hidup di dunia, kemudian dipergunakan oleh jemaat-jemaat rintisan di Asia kecil dan Eropa (Kis. 16:1-12). ${ }^{24}$

Implementasi pemuridan Kristen dalam keluarga begitu tampak dalam surat Paulus kepada Timotius, yang memberikan gambaran yang valid terhadap begitu pentingnya pendidikan atau pemuridan yang diterima Timotius sejak kecil terhadap keimanan dan keselamatanya dalam Kristus Yesus (2Tim. 3:15). ${ }^{25}$ Pemuridan Kristen dalam keluarga yang dilakukan dengan memberikan didikan oleh orang tua kepada anak-anak dengan tujuan agar anak-anak mengalami perubahan yang lebih baik dalam kepribadiannya sehingga menjadi manusia yang kedewasaan dalam kerohanian-beragama, memiliki kemandirian dalam menentukan perilaku yang baik, dan memaksimalkan segala potensi yang ada melalui intelektual kerohanian yang berkembang optimal. ${ }^{26}$ Jelas sekali keluarga memiliki peran yang sangat vital dalam pemuridan, dalam hal ini orang tua yang memegang peranan penting. Oleh sebab itu, keterlibatan orang tua yang bekerjasama dengan Gereja akan mampu memunculkan proses pemuridan Kristen dalam upaya menyelamatkan dan mendorong pertumbuhan kerohanian anak-anak.

Peranan dan teladan dari orang tua merupakan implementasi Injil keselamatan yang nyata, dapat dilihat, dapat dirasakan, dan dinikmati oleh anak-anak. Menurut John MacArthur dalam melakukan pemuridan dalam keluarga di era masa kini, ada beberapa hal yang dapat dilakukan orang tua. Pertama adalah memberikan pengajaran untuk takut akan Tuhan. Takut akan Tuhan dalam pengertian ini adalah hormat kepada Tuhan. Orang tua hendaknya selalu mengajarkan kepada anak-anak mereka untuk selalu takut akan Tuhan. Takut akan Tuhan

\footnotetext{
${ }^{23}$ Kezia Yemima, "Strategi Pembelajaran Pendidikan Agama Kristen Bagi Anak-Anak Generasi Z," STT Bethel Indonesia (2019): 6.

${ }^{24}$ Garrison, Pemuridan Yang Berhasil.

${ }^{25}$ D.A Carson and Donald Guthrie, Tafsiran Alkitab Abad Ke-21 (Jakarta: Yayasan Komunikasi Bina Kasih/OMF, 2017), 264.

${ }^{26}$ Kenzi Yemima and Yulianti, "Model Pemuridan Konseling Bagi Alumnus Perguruan Tinggi Lulusan Baru (Fresh Graduate) Yang Mengingkari Panggilan Pelayanan,” Jurnal Gamaliel : Teologi Praktika 1, no. 1 (2019): 34.
} 
adalah dasar utama dan sejati untuk memperoleh hikmat, dan hikmat inilah yang diperlukan oleh anak-anak (Amsal 1:7; 9:10). Kedua, orang tua harus mengajarkan anak-anak untuk menjaga pikiran mereka (Amsal 4:23). Merupakan tugas orang tua untuk terus membentuk pikiran dan kepribadian anak-anak berdasarkan kebenaran Firman Allah agar anak-anak memiliki karakter kebaikan, kesetiaan, kejujuran, integritas, loyalitas, serta kasih dan kebajikan. Ketiga, orang tua harus mengajarkan anak-anak mereka untuk taat kepada orang tua (Amsal 1:8). Merupakan kewajiban orang tua mendidik anak untuk taat mendengar suara kedua orang tuanya. Jika tidak ada keetaatan maka orang tua perlu mendidik anak-anak dengan disiplin dengan memberi hukuman serta peringatan bila diperlukan (Amsal 13:24). Keempat, orang tua harus mengajarkan anak-anak untuk mengasihi sesama. Mengajarkan anak-anak dengan tetap menghargai, kebaikan, kemurahan, dan belas kasihan (Galatia 5:22). Jika disimpulkan maka pengajaran yang diberikan oleh orang tua kepada anak-anaknya sesuai dengan Hukum yang utama, yang diajarkan Tuhan Yesus yaitu mengasihi Tuhan dan sesamanya (Mat. 22:37-39). ${ }^{27}$

Prinsip pemuridan Kristen dalam keluarga seperti yang di uraikan di atas, dalam pelaksanaanya di masa kini memiliki tantangan tersendiri. Hal ini terjadi karena bukan hanya anak-anak, namun orang tua yang akan berperan sebagai pengajar, pendidik dan role model, harus dapat berkomitmen dan konsisten untuk menyediakan waktu mempelajari Firman Tuhan dengan serius dan sistematis untuk kemudian mengajarkannya kepada anak-anak mereka. Jika hal ini dapat dilakukan maka anak-anak akan memiliki teladan dalam komitmen dan konsistensi. Meskipun tidak mudah, namun sebagai orang percaya yang memiliki Roh Kudus, maka para orang tua tidak berupaya dengan kekuatan sendiri untuk memuridkan anak-anak mereka dalam kebenaran Firman Tuhan melainkan dengan kekuatan yang dari Tuhan. ${ }^{28}$

\section{Membentuk Anak-anak menjadi murid Kristus di Era Disrupsi}

Pada dasarnya, keluarga merupakan tempat pertama yang sangat tepat untuk membentuk kepribadian anak-anak Kristen sebelum mereka keluar dan menghadapi realitas dunia luar di era disrupsi yang penuh tantangan. Oleh karena itu, keluarga sangat dibutuhkan untuk membentuk spiritualitas anak-anak di era disrupsi melalui peran orang tua Kristen dalam mendidik dan memuridkan anak-anak Kristen agar mengalami pertumbuhan dan kedewasaan rohani. ${ }^{29}$ Orang tua harus terus memberikan motivasi berdasarkan kebenaran, yang dibutuhkan anak-anak Kristen dalam berjuang untuk masa depan. Penghargaan yang diberikan oleh orang tua kepada anak merupakan cara yang baik, selain penghargaan dalam bentuk sikap dan ucapan, dapat juga dilakuan dengan memberikan hadiah yang menarik sebagai reward ketika anak-anak konsisten melakukan disiplin rohani seperti berdoa sebelum makan, berdoa sebelum tidur, membaca Alkitab, dan menghafal ayat Alkitab. Melalui penghargaan tersebut, anak akan

\footnotetext{
27 John MacArthur, Successfull Christian Parenting (Jakarta: Immanuel Publishing House, 2004), 133.

28 Jhon Leonardo Presley Purba, "Makna Kemah Suci Hingga Bait Allah Bagi Kehidupan Religius Kristen Masa Kini,” DANUM PAMBELUM: Jurnal Teologi dan Musik Gereja 1, no. No. 1 (2021): DPJTMG: Mei (2021): 21-36.

${ }^{29}$ Jhon Leonardo Presley Purba and Sari Saptorini, "Peran Gembala Terhadap Manajemen Pola Pemuridan Kristen Dalam 2 Timotius 2: 2 Di Era Disrupsi," DIDASKO: Jurnal Teologi dan Pendidikan Kristen 1, no. 2 (2021): 123-134.
} 
merasakan perhatian yang nyata dari orang tua sehingga mendorong mereka melakukan hal yang sama yaitu menghargai orang tua dan sesama dalam kehidupan sehari-hari sebagai seorang anak dan murid dalam sebuah keluarga. ${ }^{30}$ Didikan, motivasi, penghargaan dan penerimaan yang didapatkan anak-anak Kristen dari orang tua melalui pemuridan dalam keluarga akan berperan besar bagi mereka untuk tidak terjerumus pada pencarian jati diri dan pengakuan dari luar, yang cenderung destruktif melalui berbagai media digital yang ada di era disrupsi ini. Hal ini juga hanya mungkin terjadi ketika anak-anak Kristen dewasa secara rohani dan moral.

Karena itu, penting untuk selalu mengingat bahwa tujuan pemuridan Kristen dalam keluarga adalah untuk membentuk dan menumbuhkan spiritualitas maupun moralitas anakanak berdasarkan Firman Tuhan. Peran orang tua sangat penting dalam mendampingi anakanak. Selain sebagai orang tua bagi anak-anak, para orang tua Kristen juga harus berperan sebagai guru yang mendidik maupun mentor yang memberikan teladan dalam keluarga Kristen. Pendampingan yang dilakukan oleh orang tua di era sekarang sangat penting untuk mengontrol perkembangan anak yang sebelumnya sudah diberikan pengajaran dan didikan oleh orang tua. Apabila dalam proses pendampingan tersebut anak-anak didapati melakukan hal yang tidak sesuai dengan apa yang diajarkan oleh orang tua, perlu adanya disiplin yang diberikan kepada mereka. Penerapan disiplin penting dilakukan sebagai wujud pendampingan orang tua. Amsal 3:11-12; 19:15; 22:15, menjelaskan tentang kedisiplinan. Kitab Amsal menekankan pentingnya disiplin. Seperti keteladanan yang Tuhan ajarkan berdasarkan hukum Taurat dan jika ada anak yang lalai akan diberlakukan hukuman, namun hukuman dijalankan bukan didasari oleh kemarahan tetapi akan kasih (Amsal 3:11-12) ${ }^{31}$ Selain itu, tujuan utama dari pemuridan Kristen dalam keluarga di era disrupsi ini yaitu agar anak-anak kesetiaan dalam iman kepada Tuhan seumur hidup sehingga terbentuk generasi yang cinta dan takut akan Tuhan. Untuk dapat melakukan hal ini, khususnya di era disrupsi masa kini, janji Tuhan akan penyertaanNya selalu relevan. ${ }^{32}$ Sebagaimana telah di uraikan di atas bahwa mengimplementasikan pemuridan Kristen dalam keluarga bukanlah perkara yang mudah, terlebih di era disrupsi seperti saat ini. Namun dengan komitmen dan kesungguhan, pemuridan Kristen di era disrupsi dalam keluarga bukanlah sesuatu yang mustahil, justru dapat dilakukan dengan lebih mudah melalui pemanfaatan digitalisasi. Menurut Grace dan kolega, pendidikan dalam keluarga dapat dilakukan dengan cara membuat jadwal berlajar dan bersekutu rutin bersama anak-anak, memberikan tugas dan tanggung jawab bagi anak-anak dalam keluarga, mengontrol kegiatan anak di luar sekolah, menerapkan batasan-batasan seperti menonton televisi, waktu bermain game, memastikan teman-teman bermain anak, menciptakan suasana lingkungan rumah yang mengedukasi, penguatan kegiatan belajar, dan melatih untuk menambah wawasan dan keterampilan anak-anak sehingga anak-anak menjadi pribadi yang dewasa dan adaptif. ${ }^{33}$

\footnotetext{
${ }^{30}$ Lie, "Tantangan Dalam Pendidikan Dan Pengajaran Masa Kini."

${ }^{31}$ Sensius Amon Karlau, "Otoritas Guru PAK Dan Orang Tua," VISIO DEI: JURNAL TEOLOGI KRISTEN 2, no. 2 (2020).

${ }^{32}$ Haryono, "Model Pemuridan Berbasis Keluarga Era New Normal Pandemi Covid-19."

${ }^{33}$ Adewumi Mordeke Grace, Olojo Oludare Jethro, and Falemu Funke Aina, "Roles Of Parent On The Academic Performance Of Pupils In Elementary Schools," International Journal of Academic Research in Business and Social Sciences 2, no. 1 (2012): 197.
} 
Prinsip pendidikan umum di atas juga relevan dengan pemuridan Kristen dalam keluarga, khususnya di era disrupsi saat ini. Berikut ini langkah-langkah konkrit yang dapat diterapkan oleh orang tua dalam upaya melakukan pemuridan terhadap anak-anak mereka dalam keluarga. Pertama, orang tua harus memiliki waktu persekutuan secara pribadi dengan Tuhan sehingga anak-anak dapat melihat keteladanan melalui orang tua mereka. Kedua, orang tua harus memiliki dasar-dasar iman Kekristenan yang kokoh agar dapat mengajarkan Firman Tuhan dengan benar dan berkelanjutan kepada anak-anak. Ketiga, orang tua harus memiliki pelayanan yang produktif yang dilakukan melibatkan anak secara aktif untuk melakukan praktek secara nyata sebagai orang yang belajar pemuridan. Melalui hal ini, anak yang secara langsung terlibat dalam pelayanan aktif akan bertumbuh dewasa secara rohani maupun pribadi. Keempat, orang tua harus menyediakan waktu khusus dan teratur untuk mempelajari firman Tuhan bersama dengan anak-anak mereka. Hal ini tentu membutuhkan komitmen dan disiplin diri yang kuat agar dapat menghindari distraksi atau gangguan dari berbagai media informasi digital yang dimiliki. Hal ini tentu menjadi tantangan tersendiri di era disrupsi ini, namun harus mampu diantisipasi agar anak juga dapat melakukan hal yang sama. ${ }^{34}$

Berkaitan dengan digitalisasi di era disrupsi, Arifianto dan kolega menyimpulkan bahwa era disrupsi seperti saat ini justru telah menghadirkan berbagai kemajuan teknologi yang ditopang oleh jaringan internet sehingga semakin memudahkan pemberitataan Injil melalui digitalisasi, salah satunya adalah melalui penggunakan media sosial sebagai sarana pemberitaan Injil tanpa adanya batas tempat dan waktu sehingga semakin memperluas Kerajaan Allah di dunia ini. ${ }^{35}$ Sarana digitalisasi ini juga dapat dimanfaatkan untuk melakukan pemuridan khususnya dalam keluarga. Hal ini dapat dilakukan jika orang tua dan anak terpisah jarak maupun tempat. Dengan memanfaatkan media sosial, pemuridan dan persekutuan antara orang tua dan anak tetap dapat dilakukan secara virtual salah satunya melalui video call. Oleh karenanya, digitalisasi di era disrupsi ini justru dapat dimanfaatkan secara positif khususnya untuk pemuridan keluarga, antara orang tua dan anak.

\section{Kesimpulan}

Berdasarkan uraian di atas diketahui bahwa pemuridan Kristen dalam keluarga di era disrupsi merupakan hal yang esensial dan krusial. Orang tua berperan penting melakukan pemuridan Kristen dalam keluarga untuk mendidik dan mengarahkan anak-anak Kristen menjadi generasi yang konsisten dan bertumbuh dalam iman kepada Tuhan dan menjadi murid Kristus yang sejati. Menjadi dewasa dalam kepribadian, kerohanian dan moralitas sehingga tidak mudah terjerumus ke dalam aspek negative dari perkembangan teknologi informasi digital saat ini. Dibutuhkan komitmen dan konsistensi dalam implementasi pemuridan Kristen dalam keluarga di era disrupsi untuk menghindari distraksi atau disrupsi dari berbagai informasi media digital yang ada, sebaliknya harus menyediakan waktu yang khusus untuk melakukan pemuridan dengan memanfaatkan perkembangan digitalisasi

\footnotetext{
${ }^{34}$ MacArthur, Successfull Christian Parenting.

${ }^{35}$ Yonatan Alex Arifianto, Sari Saptorini, and Kalis Stevanus, "Pentingnya Peran Media Sosial Dalam Pelaksanaan Misi Di Masa Pandemi Covid-19," HARVESTER: Jurnal Teologi dan Kepemimpinan Kristen 5, no. 2 (2020): 86-104.
} 
teknologi informasi di era disrupsi secara positif. Salah satunya melakukan pemuridan keluarga secara virtual. Dengan demikian pemuridan Kristen dalam keluarga tetap dapat dilakukan walaupun orang tua dan anak terpisah jarak dan tempat.

\section{Referensi}

Arifianto, Yonatan Alex, and Joseph Christ Santo. "Iman Kristen Dan Perundungan Di Era Disrupsi." Angelion: Jurnal Teologi dan Pendidikan Kristen 1, no. 2 (2020).

Arifianto, Yonatan Alex, Sari Saptorini, and Kalis Stevanus. "Pentingnya Peran Media Sosial Dalam Pelaksanaan Misi Di Masa Pandemi Covid-19." HARVESTER: Jurnal Teologi dan Kepemimpinan Kristen 5, no. 2 (2020): 86-104.

Arifianto, Yonatan Alex, Reni Triposa, and Paulus Karaeng Lembongan. "Bible Study of Mission and Discipleship in the Great Commission and Its Implications for Today's Christian Life." Diegesis : Jurnal Teologi 5, no. 2 (2020): 25-42.

Barna, George. Menumbuhkan Murid-Murid Sejati. Jakarta: Metanoia, 2010.

Carson, D.A, and Donald Guthrie. Tafsiran Alkitab Abad Ke-21. Jakarta: Yayasan Komunikasi Bina Kasih/OMF, 2017.

Chan, Edmund. A Certain Kind (Yang Tertentu): Pemuridan Intensional Yang Mengubah Definisi Sukses Dalam Pelayanan. Singapore: Covenant Evangelical Free Church, 2014.

Frieda, Prima, and H.H Daniel Tamburian. "Komunikasi Antarpribadi Antara Orang Tua Dan Anak Usia Remaja Dalam Pembentukan Kepercayaan Diri Anak.” Koneksi 3, no. 2 (2020).

Garrison, Alton. Pemuridan Yang Berhasil. Malang: Gandum Mas Malang, 2016.

Grace, Adewumi Mordeke, Olojo Oludare Jethro, and Falemu Funke Aina. "Roles Of Parent

On The Academic Performance Of Pupils In Elementary Schools." International Journal of Academic Research in Business and Social Sciences 2, no. 1 (2012).

Haryono, Timotius. "Model Pemuridan Berbasis Keluarga Era New Normal Pandemi Covid19." DUNAMIS: Jurnal Teologi dan Pendidikan Kristiani 5, no. 2 (2021).

Hull, Bill. Jesus Christ, Disciplemaker. 1st ed. Surabaya: Literatur Perkantas Jawa Timur, 2015. Karlau, Sensius Amon. "Otoritas Guru PAK Dan Orang Tua." VISIO DEI: JURNAL TEOLOGI KRISTEN 2, no. 2 (2020).

Kasali, Rhenald. Self Disruption. Jakarta: Mizan Anggota IKAPI, 2018.

Lie, Tan Giok. "Tantangan Dalam Pendidikan Dan Pengajaran Masa Kini." Jurnal Teologi Stulos 12, no. 1 (2013).

Listari, Listari, and Yonatan Alex Arifianto. "Prinsip-Prinsip Misi Dari Teks Amanat Agung Bagi Pelaksanaan Misi Gereja Masa Kini.” JURNAL TEOLOGI GRACIA DEO 3, no. 1 (2020): 42-55.

MacArthur, John. Successfull Christian Parenting. Jakarta: Immanuel Publishing House, 2004. Nurjanah, Mitha. “Teori Keluarga: Studi Literatur.” Article, no. July (2019).

Provan, Iain, V. Philips Long, and Tremper Longman III. A Biblical History of Israel. Louisville, Kentucky: Westminster John Knox Press, 2003.

Purba, Jhon Leonardo Presley. "Makna Kemah Suci Hingga Bait Allah Bagi Kehidupan Religius Kristen Masa Kini.” DANUM PAMBELUM: Jurnal Teologi dan Musik Gereja 
1, no. No. 1 (2021): DPJTMG: Mei (2021): 21-36.

Purba, Jhon Leonardo Presley, and Robinson Rimun. "Kritik Terhadap Metode Tafsir Hermeneutik Pembebasan Terhadap Peristiwa Keluaran Sebagai Suatu Bentuk Pembebasan.” Jurnal Teologi Amreta 4, no. 2 (2021).

Purba, Jhon Leonardo Presley, and Sari Saptorini. "Peran Gembala Terhadap Manajemen Pola Pemuridan Kristen Dalam 2 Timotius 2: 2 Di Era Disrupsi." DIDASKO: Jurnal Teologi dan Pendidikan Kristen 1, no. 2 (2021): 123-134.

Purwoto, Paulus, Asih Rachmani Endang Sumiwi, Alfons Renaldo Tampenawas, and Joseph Christ Santo. "Aktualisasi Amanat Agung Di Era Masyarakat 5.0." DUNAMIS: Jurnal Teologi dan Pendidikan Kristiani 6, no. 1 (2021): 315-332.

Ronda, Daniel. "Kepemimpinan Kristen Di Era Disrupsi Teknologi." Evangelikal: Jurnal Teologi Injili dan Pembinaan Warga Jemaat (2019).

Sin, Sia Kok. "Adakah Metode Pemuridan Dalam Perjanjian Lama?" SOLA GRATIA: Jurnal Teologi Biblika dan Praktika 5, no. 1 (2020).

Unger, Merrill Frederick. The New Unger's Bible Handbook. Singapore: Moody Publisher, 2005.

Yemima, Kenzi, and Yulianti. "Model Pemuridan Konseling Bagi Alumnus Perguruan Tinggi Lulusan Baru (Fresh Graduate) Yang Mengingkari Panggilan Pelayanan." Jurnal Gamaliel : Teologi Praktika 1, no. 1 (2019).

Yemima, Kezia. "Strategi Pembelajaran Pendidikan Agama Kristen Bagi Anak-Anak Generasi Z." STT Bethel Indonesia (2019).

Zaluchu, Sonny Eli. "Metode Penelitian Di Dalam Manuskrip Jurnal Ilmiah Keagamaan." Jurnal Teologi Berita Hidup 3, no. 2 (2021): 249-266. 